\title{
Nontarget testing of an insect control fungus: effects of Metarhizium anisopliae on developing embryos of the inland silverside fish Menidia beryllina*
}

\author{
Fred J. Genthner, Douglas P. Middaugh \\ U.S. Environmental Protection Agency, Environmental Research Laboratory, 1 Sabine Island Drive, Gulf Breeze, \\ Florida 32561, USA
}

\begin{abstract}
Developing embryos of the inland silverside fish Menidia beryllina were exposed to conidiospores of the entomopathogenic fungus Metarhizium anisopliae. Several adverse effects were observed in both embryos and newly hatched larvae. These included transitory effects on the heart resulting in decreased cardiac output or circulation velocity, rupture of the chorion, fungal growth on the mandibles of larvae, focal vertebral abnormalities in larvae and teratogenic expressions in embryos and larvae. An ordinal ranking system was used to enumerate responses to conidiospores. This ranking system allowed significance to be determined by nonparametric analysis of variance. Responses were highly variable with significant $(p \leq 0.05)$ adverse effects observed in 5 of the 6 experiments conducted. Heat-killed spores failed to cause significant adverse effects indicating that viable spores were required for the adverse effects.
\end{abstract}

KEY WORDS: Metarhizium anisopliae - Menidia beryllina Biological control/nontarget effects

\section{INTRODUCTION}

Metarhizium anisopliae is a cosmopolitan pathogen of innumerable insect species (Vey et al. 1982). This mainly soilborne, imperfect fungus has received world-wide attention for the control of a variety of insect pests. Its most extensive and successful use as a biocontrol agent has been in Brazil where, produced under the name Metaquino ${ }^{(B)} \cdot$, it is sprayed on sugar cane fields to control the spittle bug Mahanarva posticata (Moscardi 1989). In Australia M. anisopliae may soon be commercialized for control of the subterranean pasture scarab Adoryphorus couloni. In tests with a granulated formulation of $M$. anisopliae, Bio-Green ${ }^{\circledR}$,

\footnotetext{
- Contribution No. 898, Environmental Research Laboratory. U.S. EPA, Gulf Breeze

- Mention of tradenames or commercial products does not imply endorsement by the U.S. Environmental Protection Agency
}

1 application proved effective against the pasture scarab for over 4 yr (Drummond 1994). In May 1993 M. anisopliae was registered by the U.S. Environmental Protection Agency for control of nuisance flies and cockroaches. For this application $M$. anisopliae is introduced in a patented bait-station, Bio-Path ${ }^{(B)}$, where exposed insects can spread the fungus through direct contact.

With the exception of insects, little is known about the effects of this organism on cold-blooded animals. In aquatic animals, no problems with Metarhizium anisopliae have been reported. Donovan-Peluso et al. (1980) reported that exposing frogs to $M$. anisopliae spores by gastric intubation produced no pathologic lesions or infection of viscera. However, a related insect pathogenic fungus, Beauveria bassiana, caused a fatal infection in a captive alligator (Fromtling et al. 1979). Recently, we adapted a chemical toxicity and teratogenicity test that utilized developing embryos of the inland silverside fish Menidia beryllina to evaluate 
potential toxicity and pathogenicity of $B$. bassiana (Genthner \& Middaugh 1992, Middaugh \& Genthner 1994). Various adverse effects were observed in the embryos including rupture of the chorion, developmental defects (vertebral abnormalities) and death; in the hatched larvae, fungal infections on the mandibles and vertebral abnormalities were noted.

Because of the recent commercialization of products based on Metarhizium anisopliae and the possibility that this fungus may possess a host-range different from Beauveria bassiana, potential adverse effects of M. anisopliae on developing Menidia beryllina embryos were investigated. We report significant adverse effects including one not observed with $B$. bassiana. Exposure to this particular strain of $M$. anisopliae caused developmental effects that were less severe than those observed with $B$. bassiana-grasshopper strain $(\mathrm{GH})$.

\section{MATERIALS AND METHODS}

Cultivation of fungus and recovery of spores. Metarhizium anisopliae 683 (USDA-ARS collection of entomopathogenic fungal cultures, Ithaca, NY, USA) was obtained from Rosalind James, ManTech Environmental Technology, Corvallis, OR, USA.

The fungus was cultured at $25^{\circ} \mathrm{C}$ on glucose-yeast extract-basal salts agar medium (GYBS) (Boucias et al. 1988). At 5 to 12 d post-inoculation, progeny conidiospores were harvested by scraping confluent mycelial mats with a sterile spatula. Conidia were suspended in sterile, moderately hard water (MHW) (U.S. EPA 1991) by gentle aspiration in a hand-held tissue homogenizer. Spore density was adjusted to approximately $1 \times 10^{8}$ spores $\mathrm{ml}^{-1}$, using a hemocytometer. Spore suspensions were either used immediately or allowed to soak for $24 \mathrm{~h}$ (Table 1). Viable spore counts were performed by diluting spores in sterile distilled water containing $0.03 \%$ Triton X-100 (Union Carbide, Indianapolis, IN, USA) and spreading the dilutions onto GYBS. Fungal colonies were counted after $5 \mathrm{~d}$.

To prove virulence, corn earworm Helicoverpa zea were exposed to Metarhizium anisopliae by dipping 2nd instar caterpillars into a conidiospore suspension (ca $1 \times 10^{7} \mathrm{ml}^{-1}$ ). Five exposed caterpillars were placed in a Petri dish at $25^{\circ} \mathrm{C}$ containing approximately $3 \mathrm{~g}$ of a sterile diet consisting of ground raw pinto beans, $14 \mathrm{~g}$; wheat germ, $10 \mathrm{~g}$; torula yeast, $6.3 \mathrm{~g}$; casein $5.0 \mathrm{~g}$; agar, $2.3 \mathrm{~g}$; and distilled water, $135 \mathrm{ml}$. Three days after exposure, dead caterpillars displaying external conidiogenesis were stored frozen at $-80^{\circ} \mathrm{C}$ in $20 \%$ glycerol. Frozen caterpillars were thawed at room temperature and homogenized in sterile water. A loopful of the homogenate was streaked onto a GYBS +
Table 1. Chronology and treatment of Metarhizium anisopliae (ARSEF No. 683, received 9 March 1992) conidiospores used in Expts $A$ through $F$. In Expts $B$ and $C$, spore suspensions were incubated at $25^{\circ} \mathrm{C}$. for $24 \mathrm{~h}$ ('soaked' before embryo exposures\}
Expt Chronology and treatment of conidiospores
A 1 July 1992, spores tested after passage through corn earworm Helicoverpa zea isolated on GYBS + $\mathrm{Nx}$, spores produced on GYBS, harvested from a $12 \mathrm{~d}$ old culture
B 29 September 1992; spores from Expt A tested after 2 additional saprophytic passages on GYBS
C 22 December 1992; spores from Expt A tested after 2 additional saprophytic passages on GYBS
D 8 September 1993; spores from dead corn earworm which was stored frozen, isolated on GYBS + Nx spores produced on GYBS
E 22 September 1993; spores from dead corn ear- worm which was stored frozen, isolated on GYBS + $\mathrm{Nx}$, spores produced on GYBS
F 25 October 1993; spores from dead corn earworm which was stored frozen, isolated on GYBS $+\mathrm{Nx}$, spores produced on GYBS

nalidixic acid ( $\mathrm{Nx}, 0.5 \mathrm{mg} \mathrm{m}^{-1}$ ) plate. Isolated colonies of $M$. anisopliae were selected to produce conidiospores on $\mathrm{Nx}$-free GYBS for exposure experiments.

Metarhizium anisopliae was recovered from exposed embryos and larvae by washing them (twice in $100 \mathrm{ml}$ sterile water) to eliminate the spores carried over in water from the exposure tubes and then homogenizing the tissue and spreading dilutions onto the surface of GYBS + Nx plates. Fungal colonies were identified as $M$. anisopliae by their blue-green color, size and shape of conidiospores, and pathogenicity to corn earworm.

Embryo tests. Embryonic inland silversides Menidia beryllina were obtained from adults that spawned naturally in the laboratory at $5 \%$ salinity and $25^{\circ} \mathrm{C}$ as described by Middaugh et al. (1987, 1988). The photoperiod was $16 \mathrm{~h}$ light and $8 \mathrm{~h}$ darkness. Light intensity at the water's surface in brood tanks was approximately $17 \mu$ Ein $\mathrm{m}^{-2} \mathrm{~s}^{-1}$.

Embryo exposures were performed as described previously (Genthner \& Middaugh 1992). Single embryos were placed in Leighton ${ }^{\circledast}$ culture tubes. Sterile MHW (6ml) as added to each control tube, and $6 \mathrm{ml}$ of $1 / 10$ serial dilutions of the conidiospore suspensions was added to each exposure tube. A killed conidiospore control was provided from the dilution containing the highest conidiospore density by sterilization in an autoclave $\left[20 \mathrm{~min}, 15 \mathrm{lb} \mathrm{in}^{-2}\left(=10^{5} \mathrm{~Pa}\right)\right]$. This design yielded a 'no exposure' control, a 'heat-killed' control, and three 10-fold dilutions of conidiospores 
with 30 replicate embryos for each treatment. Exposure tubes were maintained in a horizontal position and incubated at $25^{\circ} \mathrm{C}$. The photoperiod was $14 \mathrm{~h}$ light and $10 \mathrm{~h}$ darkness. Light intensity was ca $20 \mu \mathrm{Ein} \mathrm{m}^{-2}$ $5^{-1}$ (Genthner \& Middaugh 1992). The observed effects in embryonic and larval Menidia beryllina were scored daily on the basis of the responses described in Table 2. Cardiac output was measured by timing the contractions of the heart muscle. If a normally developing heart was absent, the pulsations of precursor tissue was counted. Observations were made with a Zeiss Axiovert ${ }^{*}$ inverted microscope equipped for photomicrography.

At the end of each 7 to $9 \mathrm{~d}$ experiment, scores for each embryo were summed. This procedure resulted in 30 individual ranks for each of the 4 to 5 treatments in each experiment. The nonparametric Kruskal-Wallis Analysis of Variance (KW-ANOVA) by ranks was conducted to determine if the rank scores for each treatment within an experiment differed significantly ( $\mathrm{p} \leq$ 0.05) (Statsoft Inc. 1991). This test assumes that the variables (respective embryo responses at differing conidiospore concentrations) under consideration were measured on at least an ordinal (rank order) scale as shown in Table 2 . In experiments where statistically significant differences were detected with the KWANOVA, post hoc (pair-wise comparisons) were conducted to determine if the rank scores for the control embryos and each of the conidiospore concentrations were significantly different $(\alpha \leq 0.05)$ from each other (Siegel \& Castellan 1988)

In addition to the nonparametric KW-ANOVA, a parametric 1-way analysis of variance (ANOVA) and Tukey HSD post hoc test were conducted to determine if the number of 'hatched-normal' larvae in control

Table 2. Effects of Metarhizium anisopliae conidiospores on embryonic and larval inland silversides Menidia beryllina.

Ordinal values were used to determine significant effects

Effect on embryos or larvae $\begin{gathered}\text { Assigned } \\ \text { ordinal value }\end{gathered}$

Normal, no response in controls or

treatments (see Figs. 2A \& 3A)

Transitory effect on heart including a decrease 1 in cardiac output or circulation velocity

Rupture of chorion (see Fig. 2C)

Fungal growth on mandible of hatched larva (see Fig. 3D)

Focal vertebral abnormality in hatched larva

Teratogenic expression in embryo or hatched larva (see Figs. 2B \& 3B)

Death of developing embryo treatments and each of the conidiospore density treatments were significantly different $(\alpha \leq 0.05)$ (Statsoft Inc. 1991). In this analysis, the 30 embryos in each treatment were divided into 3 replicate groups of 10 each to provide 3 replicates per treatment. The first 10 embryos in each treatment were assigned to the first replicate, the next 10 to the second replicate and the final 10 to the third replicate. All 'hatched-normal' larvae in a treatment were assigned a value of 1 and all 'not-hatched' or 'hatched-not-normal' larvae a value of 0 . The values for the 10 embryos in each replicate were summed prior to conducting the 1-way ANOVA.

\section{RESULTS}

Developing embryos of Menidia beryllina were exposed to conidiospores of Metarhizium anisopliae in 6 separate experiments (A to F; Fig. 1). The date each experiment was performed and history of conidiospore culture is presented in Table 1

There was substantial variability in the observed effects of Metarhizium anisopliae within and among experiments (Table 3, Fig. 1). In Expt A, spores were tested after passage through the corn earworm Helicoverpa zea (Table 1). The KW-ANOVA and post hoc analyses revealed statistically significant differences from the control at all 3 conidiospore densities (Table 3). These differences were largely the result of a reduction in cardiac output (approximately 50\%) during Day 2 of conidiospore exposure (Table 4). This transitory effect was not observed on subsequent days and there was no apparent adverse effect on the course of normal development and successful hatching of embryos (Fig. 1A). The parametric 1-way ANOVA and post hoc test for hatch data revealed no significant differences between the numbers of 'hatched normal' larvae for the control and each of the conidiospore treatments (Table 4).

In Expt B, conidiospores from Expt A were produced after 2 additional saprophytic passages of Metarhizium anisopliae on GYBS plates (Table 1). Statistically significant differences from the control response were obtained at the intermediate and high conidiospore density treatments but not in the low spore treatment of $1.0 \times 10^{4} \mathrm{ml}^{-1}$ (Table 3, Fig. 1B).

At the intermediate spore density several embryo responses were observed. A slight to moderate reduction in the size and structure of the craniofacial complex was often associated with a failure of the heart to develop normally. The severity of these cardiac manifestations ranged from a lack of a discernible heart, to a 'tube' heart lacking chambers incapable of normal cardiac output, to a structurally normal looking heart that displayed a transient reduction in cardiac output. 

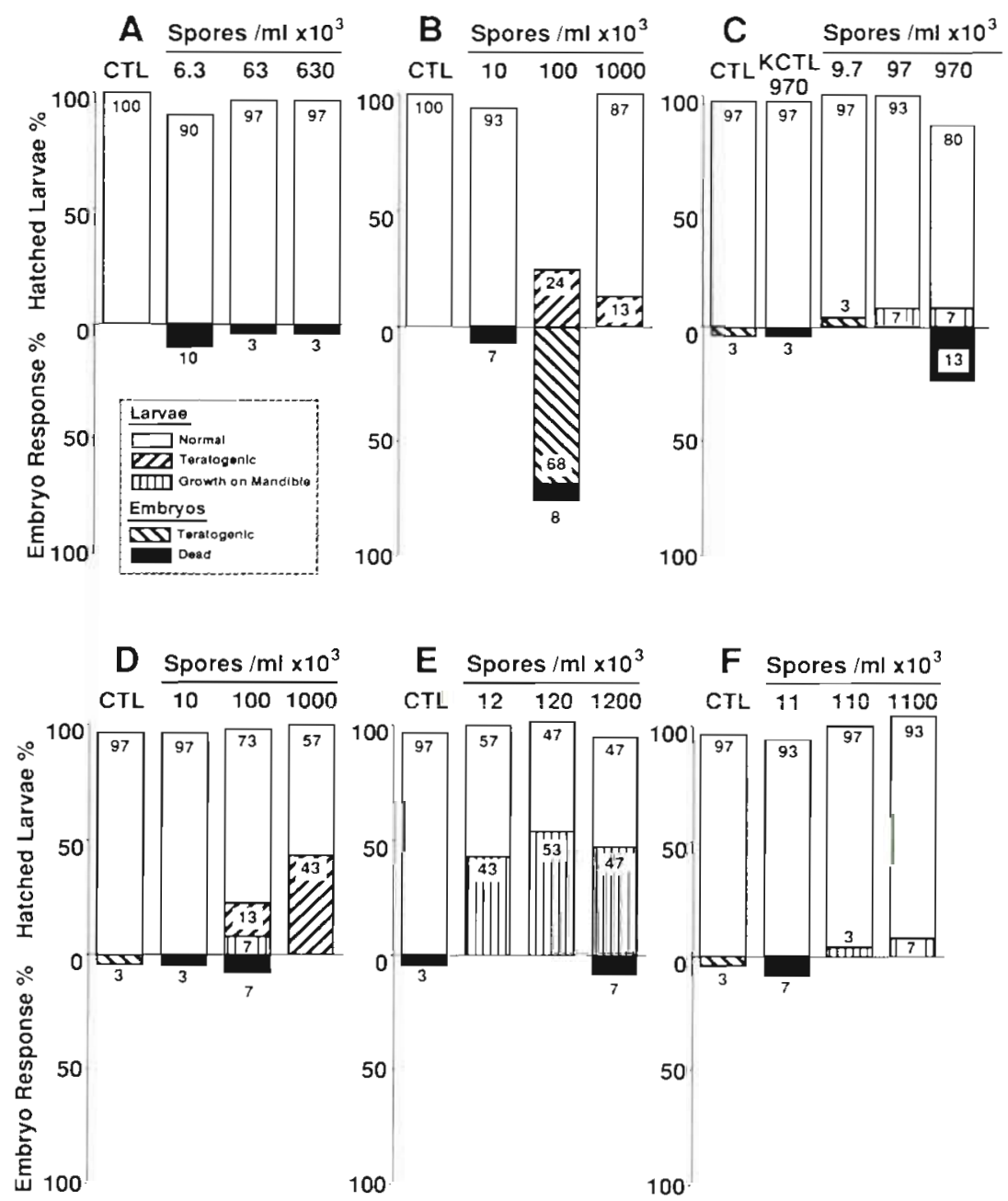

Fig. 1 Responses of embryonic and larval inland silversides Menidia beryllina to conidiospores of Metarhizium anisopliae in Expts A to F. Note considerable variation in responses within and among the 6 experiments. Teratogenic responses in embryos and larvae included skeletal defects as well as focal vertebral abnormalities as defined in Table 2 and shown in Figs. 2B \& $3 \mathrm{~B}$. Growth of fungal hyphae on the mandibles of hatched larvae was also a common occurrence in the final 4 experiments. CTL: no spores control; KCTL: heatkilled spores control

Skeletal abnormalities included a slight-to-moderate stunting of the skeletal axis, and in some cases the presence of gross vertebral abnormalities resulting in the lack of any organized structures or vertebrae (compare Fig. 2A to Fig. 2B). Embryo rupture was also occasionally observed (Fig. 2C). Germinating conidia on the surface of a ruptured embryo (Fig. 2D) suggested that penetration of the chorion by the fungus caused the rupture. Spreading dilutions of homogenized embryos onto the surface of GYBS + Nx plates revealed that dead embryos exposed at the intermediate spore density possessed approximately $4 \times 10^{3}$ colony forming units of Metarhizium anisopliae per embryo while living embryos possessed only about 75 colony forming units of Metarhizium anisopliae per embryo. Metarhizium anisopliae was never isolated from controls.

In Expt B, only 7 ( $24 \%$ ) of the 30 embryos exposed at the intermediate spore density $\left(1.0 \times 10^{5} \mathrm{ml}^{-1}\right)$ hatched. The hatched larvae showed deformities similar to the ones described above for developing embryos (Fig. 3).
While statistically significant responses were obtained at the highest spore density (Table 3), they were more severe at the intermediate density (Fig. 1B). All embryos exposed at the high spore density hatched; however, many exhibited a persistent reduction in cardiac output from Day 2 to hatching that appeared to be very similar, if not identical, to the transitory cardiac response observed in Expt A. Although this reduction in cardiac output persisted until hatch, there was no apparent detrimental effect on the developing embryos or hatched larvae nor was hatching delayed. Moreover, the ANOVA comparison revealed that differences in the number of control versus conidiospore exposed individuals that 'hatched-normal' was significantly different only for the intermediate exposure density $\left(1.0 \times 10^{5}\right.$ spores $\mathrm{ml}^{-1}$; Table 4$)$.

Although conidiospores used in Expts B and $C$ were cultured from the same source (Table 1), no significant responses were obtained in Expt C (Table 3). A single 'no spore' control embryo, however, had a teratogenic response characterized by a moderate reduction in size 
Table 3. Responses of Menidia beryllina to Metarhizium anisopliae. Summary of the Kruskal-Wallis (KW) ANOVA and post hoc analyses of data from Expts $A$ through $F$. Treatment values are direct counts. ns: not significant

\begin{tabular}{|c|c|c|c|c|c|c|}
\hline Expt & KW & $\mathrm{df}$ & ANOVA $p$ & $\begin{array}{c}\text { Treatment } \\
\text { (spores } \mathrm{ml}^{-1} \text { ) }\end{array}$ & $R_{\text {, rank }}$ & $\alpha$ \\
\hline A & 104.56 & 3 & $\leq 0.001$ & $\begin{array}{c}\text { Control }(0) \\
6.3 \times 10^{3} \\
6.3 \times 10^{4} \\
6.3 \times 10^{5}\end{array}$ & $\begin{array}{l}15.5 \\
77.1 \\
73.9 \\
75.4\end{array}$ & $\begin{array}{l}-\overrightarrow{ } \\
\leq 0.05 \\
\leq 0.05 \\
\leq 0.05\end{array}$ \\
\hline B & 101.11 & 3 & $\leq 0.001$ & $\begin{array}{c}\text { Control }(0) \\
1.0 \times 10^{4} \\
1.0 \times 10^{5} \\
1.0 \times 10^{6}\end{array}$ & $\begin{array}{c}29.5 \\
35.4 \\
103.5 \\
73.5\end{array}$ & $\begin{array}{c}- \\
\text { ns } \\
\leq 0.05 \\
\leq 0.05\end{array}$ \\
\hline C & 9.31 & 3 & $\geq 0.050$ & $\begin{array}{c}\text { Control (0) } \\
\text { Control } \\
\text { (killed) } \\
9.5 \times 10^{3} \\
9.5 \times 10^{4} \\
9.5 \times 10^{5}\end{array}$ & $\begin{array}{l}72.5 \\
72.6 \\
72.5 \\
74.8 \\
85.1\end{array}$ & $\begin{array}{l}- \\
\text { ns } \\
\text { ns } \\
\text { ns } \\
\text { ns }\end{array}$ \\
\hline $\mathrm{D}$ & 24.18 & 3 & $\leq 0.001$ & $\begin{array}{c}\text { Control }(0) \\
1.0 \times 10^{4} \\
1.0 \times 10^{5} \\
1.0 \times 10^{6}\end{array}$ & $\begin{array}{l}51.2 \\
51.4 \\
64.6 \\
74.8\end{array}$ & $\begin{array}{c}- \\
\text { ns } \\
\text { ns } \\
\leq 0.05\end{array}$ \\
\hline E & 19.94 & 3 & $\leq 0.001$ & $\begin{array}{c}\text { Control }(0) \\
1.2 \times 10^{4} \\
1.2 \times 10^{5} \\
1.2 \times 10^{6}\end{array}$ & $\begin{array}{l}40.2 \\
62.8 \\
68.7 \\
70.2\end{array}$ & $\begin{array}{c}- \\
\leq 0.05 \\
\leq 0.05 \\
\leq 0.05\end{array}$ \\
\hline $\mathrm{F}$ & 0.72 & 3 & $\geq 0.870$ & $\begin{array}{c}\text { Control }(0) \\
1.1 \times 10^{4} \\
1.1 \times 10^{5} \\
1.1 \times 10^{6}\end{array}$ & $\begin{array}{l}59.5 \\
61.6 \\
59.5 \\
61.4\end{array}$ & $\begin{array}{l}- \\
\text { ns } \\
\text { ns } \\
\text { ns }\end{array}$ \\
\hline
\end{tabular}

Table 4. Responses of Menidia beryllina to Metarhizium anisopliae. Comparison of the nonparametric Kruskal-Wallis ANOVA. and post hoc analyses (KW-ANOVA) to the parametric 1-way ANOVA and Tukey post hoc analyses (1-way ANOVA) for 'normal' hatched larvae. Controls compared to treatments (values are direct counts). ns: not significant

\begin{tabular}{|c|c|c|c|c|}
\hline Expt & $\begin{array}{l}\text { Treatment } \\
\text { (spores } \mathrm{ml}^{-1} \text { ) }\end{array}$ & KW-ANOVA & 1-way ANOVA & Reasons for differences \\
\hline$A$ & $\begin{array}{l}6.3 \times 10^{3} \\
6.3 \times 10^{4} \\
6.3 \times 10^{5}\end{array}$ & $\begin{array}{l}\leq 0.05 \\
\leq 0.05 \\
\leq 0.05\end{array}$ & $\begin{array}{l}\text { ns } \\
\text { ns } \\
\text { ns }\end{array}$ & $\begin{array}{l}\text { Due to a transient reduction in cardiac output on Day } 2 \text { of } \\
\text { embryo exposure (KW-ANOVA) }\end{array}$ \\
\hline B & $\begin{array}{l}1.0 \times 10^{4} \\
1.0 \times 10^{5} \\
1.0 \times 10^{6}\end{array}$ & $\begin{aligned} & \mathrm{ns} \\
& \leq 0.05 \\
& \leq 0.05\end{aligned}$ & $\begin{array}{l}\mathrm{ns} \\
\leq 0.05 \\
\mathrm{~ns}\end{array}$ & $\begin{array}{l}\text { Due to a reduction in cardiac output on Days } 2 \text { through } 6 \text { of } \\
\text { embryo exposure (KW-ANOVA) }\end{array}$ \\
\hline C & $\begin{array}{c}\text { Control (killed) } \\
9.5 \times 10^{3} \\
9.5 \times 10^{4} \\
9.5 \times 10^{5}\end{array}$ & $\begin{array}{l}\text { ns } \\
\text { ns } \\
\text { ns } \\
\text { ns }\end{array}$ & $\begin{array}{l}\text { ns } \\
\text { ns } \\
\text { ns } \\
\text { ns }\end{array}$ & No differences \\
\hline $\mathrm{D}$ & $\begin{array}{l}1.0 \times 10^{4} \\
1.0 \times 10^{5} \\
1.0 \times 10^{6}\end{array}$ & $\begin{aligned} & n s \\
& n s \\
& \leq 0.05\end{aligned}$ & $\begin{aligned} & n s \\
\leq & 0.05 \\
\leq & 0.05\end{aligned}$ & $\begin{array}{l}\text { Due to skeletal abnormality and skeletal stunting observed } \\
\text { in hatched larvae (ANOVA) }\end{array}$ \\
\hline E & $\begin{array}{l}1.2 \times 10^{4} \\
1.2 \times 10^{5} \\
1.2 \times 10^{6}\end{array}$ & $\begin{array}{l}\leq 0.05 \\
\leq 0.05 \\
\leq 0.05\end{array}$ & $\begin{array}{l}\text { ns } \\
\leq 0.05 \\
\leq 0.05\end{array}$ & $\begin{array}{l}\text { Due to fungal growth on the mandibles of hatched larvae } \\
\text { (KW-ANOVA) }\end{array}$ \\
\hline $\mathrm{F}$ & $\begin{array}{l}1.1 \times 10^{4} \\
1.1 \times 10^{5} \\
1.1 \times 10^{6}\end{array}$ & $\begin{array}{l}\text { ns } \\
\text { ns } \\
\text { ns }\end{array}$ & $\begin{array}{l}\text { ns } \\
\text { ns } \\
\text { ns }\end{array}$ & No differences \\
\hline
\end{tabular}



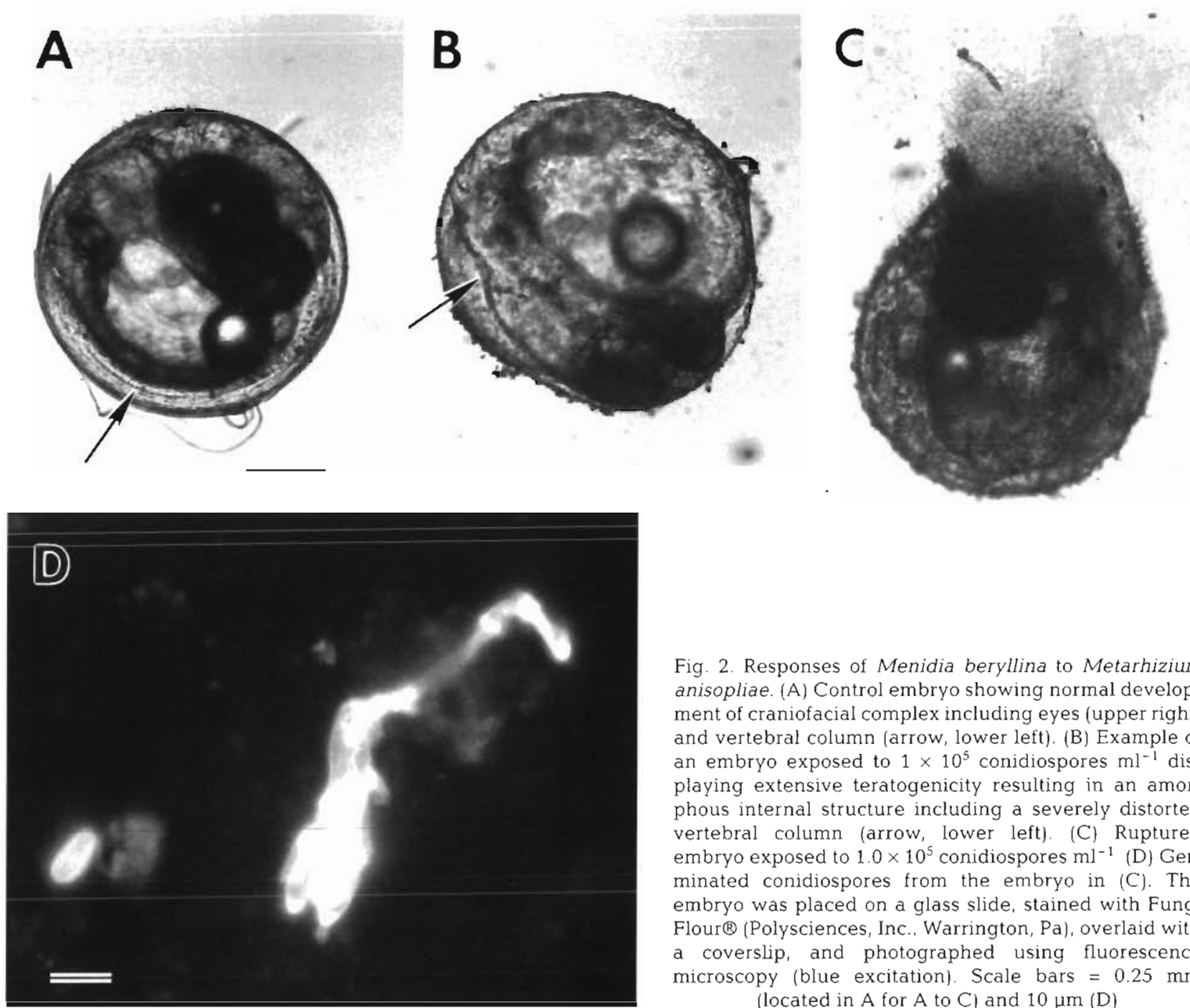

Fig. 2. Responses of Menidia beryllina to Metarhizium anisopliae. (A) Control embryo showing normal development of craniofacial complex including eyes (upper right) and vertebral column (arrow, lower left). (B) Example of an embryo exposed to $1 \times 10^{5}$ conidiospores $\mathrm{ml}^{-1}$ displaying extensive teratogenicity resulting in an amorphous internal structure including a severely distorted vertebral column (arrow, lower left). (C) Ruptured embryo exposed to $1.0 \times 10^{5}$ conidiospores $\mathrm{ml}^{-1}$ (D) Germinated conidiospores from the embryo in (C). The embryo was placed on a glass slide, stained with Fungi Flour@ (Polysciences, Inc., Warrington, Pa), overlaid with a coverslip, and photographed using fluorescence microscopy (blue excitation). Scale bars $=0.25 \mathrm{~mm}$ (located in A for A to C) and $10 \mu \mathrm{m}$ (D)

of the craniofacial complex, an amorphous heart and a stunted skeletal axis. This individual died prior to hatching (Fig. 1C). A single embryo exposed at the low spore density $\left(9.7 \times 10^{3} \mathrm{ml}^{-1}\right)$ also showed slight stunting of the skeletal axis at hatching. The ANOVA revealed no significant differences in numbers of 'hatched normal' larvae for control, killed-control, and conidiospore exposed groups (Table 4)

Metarhizium anisopliae, isolated from an infected corn earworm stored frozen in $20 \%$ glycerol, was used to produce conidiospores for Expt D (Table 1). Statistically significant larval responses occurred at the high $\left(1.0 \times 10^{6} \mathrm{ml}^{-1}\right)$ conidiospore density (Table 3$)$ where 13 out of $30(43 \%)$ larvae had skeletal abnormalities (Fig. 1D). While not statistically significant, growth of Metarhizium anisopliae on the mandibles of 2 larvae at the intermediate spore density, and vertebral abnormalities with slight stunting of the skeletal axes was apparent in 4 larvae on the day of hatching. The ANOVA revealed significant differences in the number of 'hatched normal' control larvae and larvae from embryos exposed at the intermediate and high conidiospore densities (Table 4).

For Expt E, conidiospores were cultured from the same source as in Expt D. In this experiment, however, no teratogenic effects were observed in the larvae (Fig. 1E). Instead, growth of Metarhizium anisopliae was observed on the mandibles of newly hatched larvae exposed at all 3 conidiospore densities (Fig. 3D). The KW-ANOVA and post hoc tests revealed that all conidiospore densities resulted in responses that were statistically different from the controls (Table 3). The ANOVA and post hoc test also revealed significant differences between the number of 'hatched-normal' control larvae and larvae from embryos exposed at the intermediate and high conidiospore densities (Table 4). 

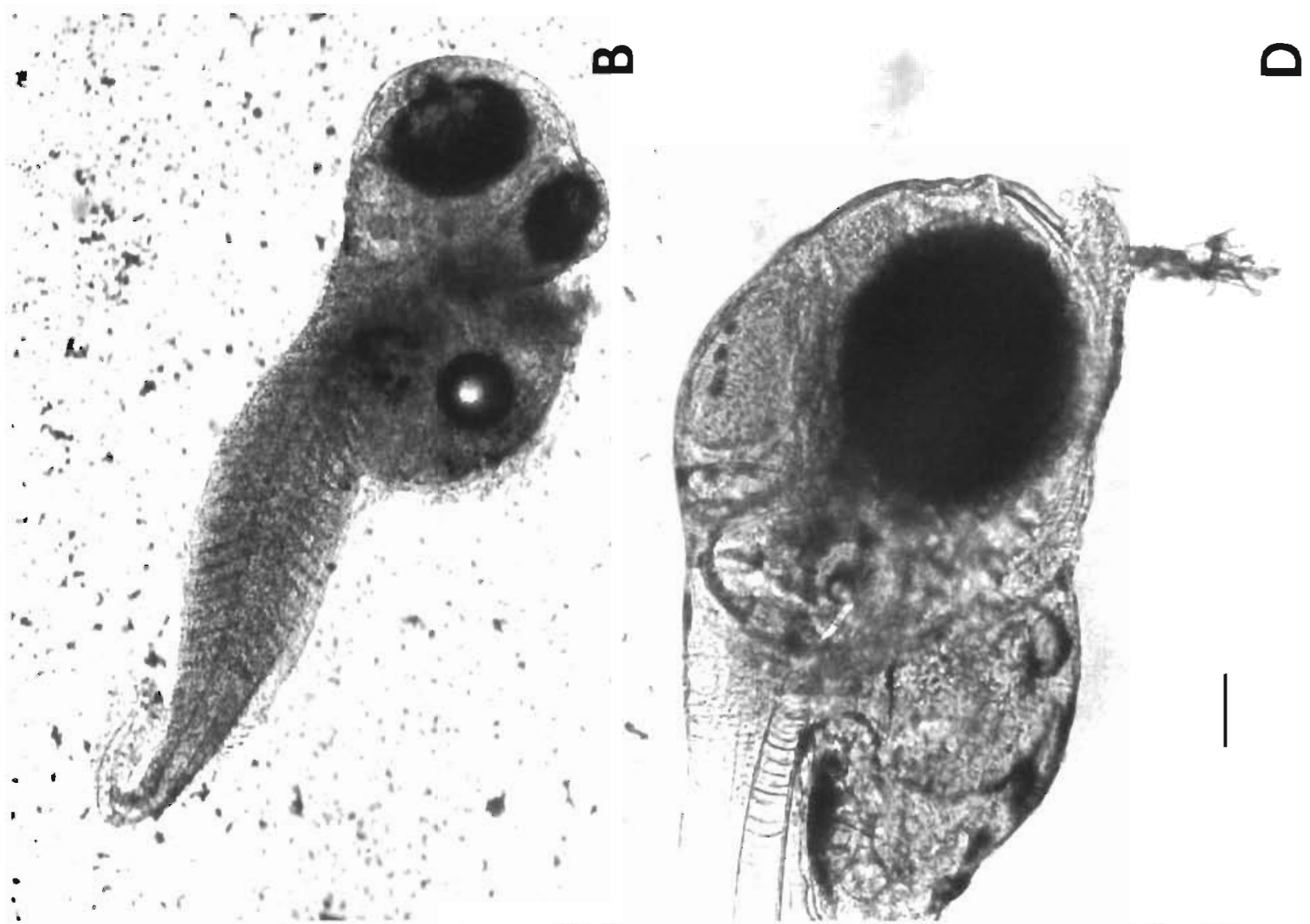

늘

है

छ

豆

畐

焉

흘

흠

ㄱㅇㅇ

ह

$\times$ 号范

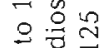

응

웅

$\times$

실

过

4
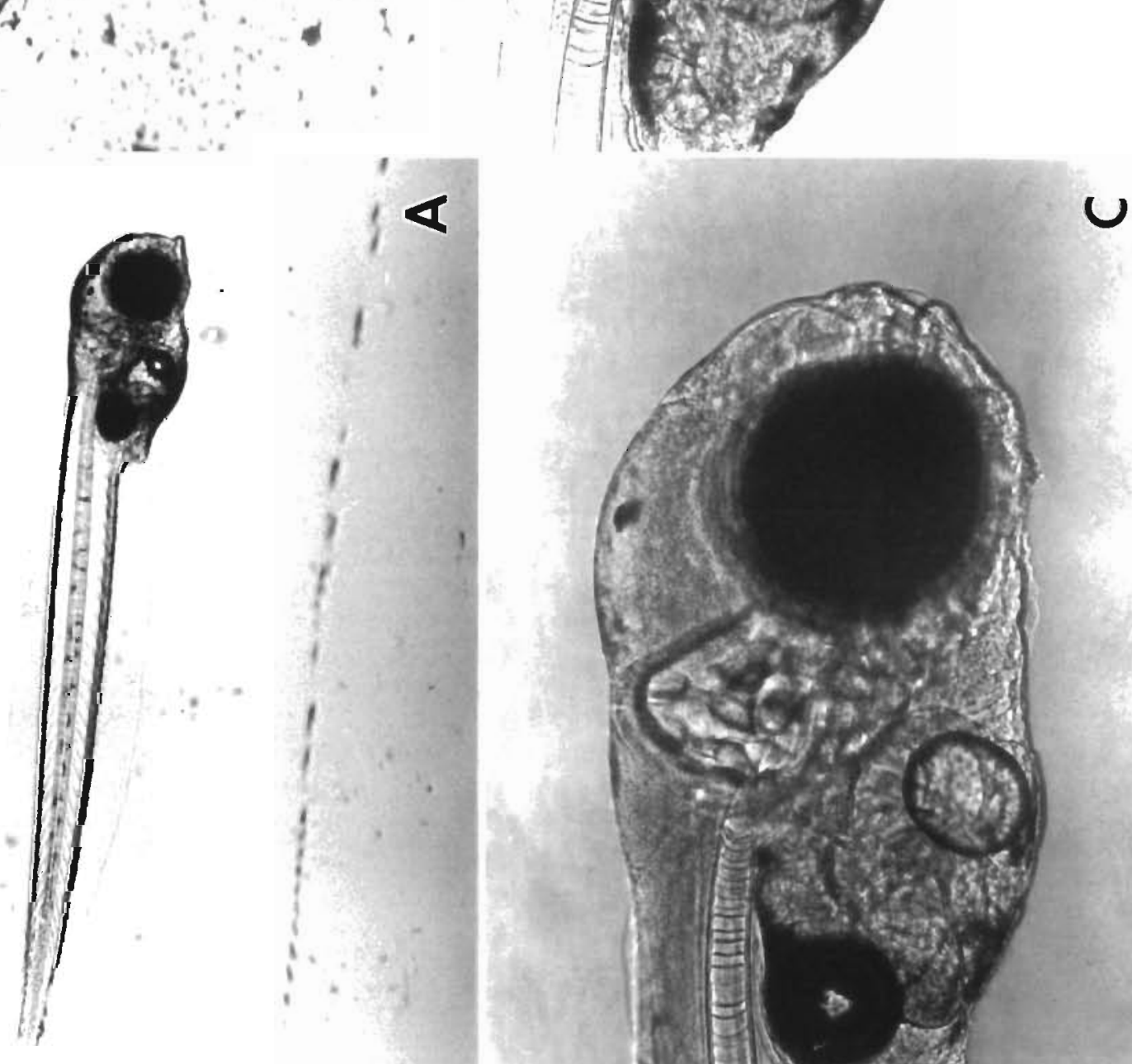

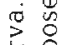

范安

엉ㅇำ

총

드응

$\cup \frac{0}{0}$

응

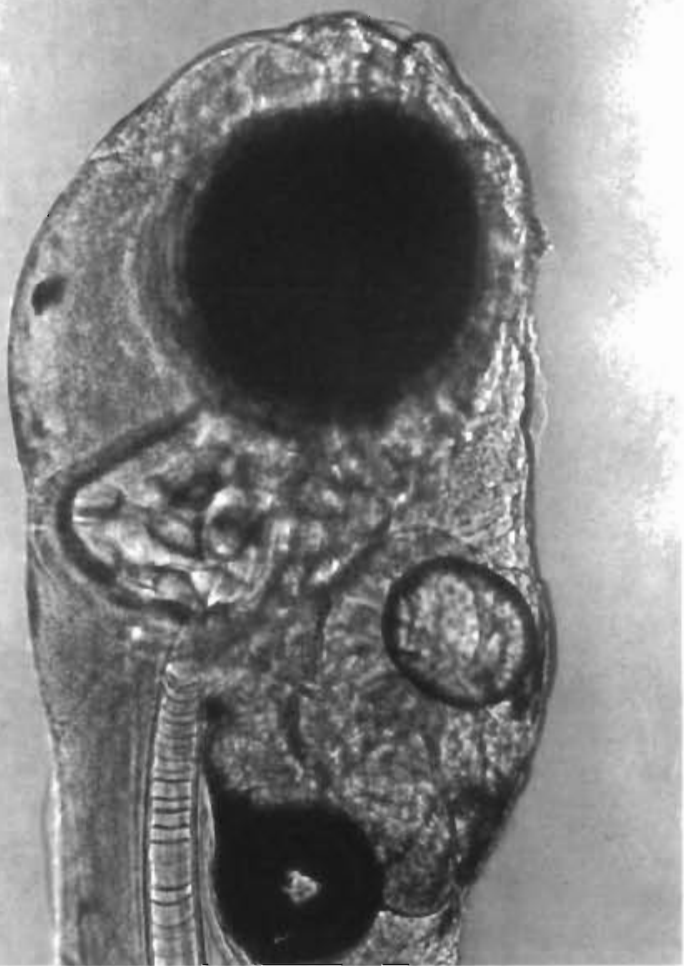

उ马

过苟

है

ह

记过

곤

过苛

$\circ \frac{9}{8}$

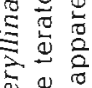

0.3

(马)

ฮี

$\sum 0$

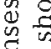

․ำ

ปे

i 응

क्षे 
For Expt F, spores were cultured from the same source as in Expts D and E (Table 1). Responses in Expt $F$ resembled those observed in Expt $C$ (Fig. 1C, F). A single control embryo displayed teratogenicity that included a slight reduction in the size of the craniofacial complex and reduced cardiac output. Conidiospore exposed embryos showed a nearly complete and normal survival and hatch with only a few of the larvae from the intermediate and high conidiospore treatment groups showing growth of Metarhizium anisopliae on their mandibles. The KW-ANOVA indicated that none of these observed effects were statistically different from control responses (Table 3). The ANOVA also indicated that there were no significant differences between the number of 'hatched-normal' control larvae and larvae from embryos exposed at the 3 conidiospore densities (Table 4 ).

\section{DISCUSSION}

In previous studies, we exposed fish embryos to conidiospores of Beauveria bassiana, an insect pathogenic fungus related to Metarhizium anisopliae, and observed several adverse effects (Genthner \& Middaugh 1992, Middaugh \& Genthner 1994). In the current study, the adverse effects we observed in $M$. anisopliae exposed embryos were similar to, although less severe than, those obtained with $B$. bassiana. An exception was a transitory effect on the embryo heart that resulted in a decrease in cardiac output or circulation velocity. Observed in Expts A and B, this response was not unique to $M$. anisopliae exposed embryos. Reductions in cardiac output, typically between 20 and $60 \%$, have also been observed in embryos exposed to fractions of partially degraded crude oil (D. Middaugh unpubl.). In these oil tests, however, delayed hatch and other adverse effects often followed reductions in cardiac output.

As with partially degraded crude oil, the cardiac response with Metarhizium anisopliae suggested some form of toxin involvement. $M$. anisopliae produces several toxic secondary metabolites, the precise role of which in pathogenesis and virulence remains unclear (Gillespie \& Claydon 1989). It is possible that mycotoxins were produced by conidiospores germinating on the surface of the embryos. These mycotoxins may have elicited a narcotic effect on the embryos with no lasting adverse effects on embryogenesis or larval hatching Transport of the mycotoxin through the chorion may not be necessary to produce this effect since at least one mycotoxin, destruxin $E$, was shown to possess 'contact' activity (Poprawski et al. 1994). The other more severe and permanent effects such as vertebral abnormalities (focal and stunting) could also have resulted from the action of mycotoxins. It is also possible that a cardiac response was absent in embryos exposed to Beauveria bassiana (Middaugh \& Genthner 1994) because mycotoxins produced by this fungus are different than those produced by $M$. anisopliae.

Highly variable responses were common in tests with embryos exposed to Beauveria bassiana and Metarhizium anisopliae (Genthner \& Middaugh 1992, Middaugh \& Genthner 1994, this study). In the present study, 2 procedures were tested to attain an invariable, virulent response between tests. First, conidiospores were consistently produced from $M$. anisopliae recently isolated from corn earworm (Table 1). Thus, the culture had not been repeatedly subcultured on solid media, a practice that may decrease virulence. Second, $M$. anisopliae conidiospore suspensions were incubated in $\mathrm{MHW}$ at $25^{\circ} \mathrm{C}$ for $24 \mathrm{~h}$ before testing (Table 1). Dillon \& Charnley (1985) reported that soaking conidiospores of $M$. anisopliae in distulled water accelerated and synchronized germination. Soaked conidiospores of $M$. anisopliae were also more virulent towards the tobacco hornworm Manduca sexta than were non-soaked conidiospores (Hassan \& Charnley 1983). In our study, soaking of conidiospores did not produce consistent results (compare Expts B and C). Thus, we can only conclude that unexpected changes in virulence, as reported by Weiser (1982), may have contributed to response variability.

Statistically significant responses were detected by the KW-ANOVA and ANOVA tests (Tables 3 \& 4) These analyses yielded differences in significance in 10 out of 18 viable conidiospore treatments (Table 4). In Expts $A$ and $B$, significant differences from control responses were detected by the KW-ANOVA post hoc test for 5 of 6 conidiospore densities (Table 4). In contrast, the ANOVA and post hoc test revealed only 1 conidiospore density that was significantly different from controls (Table 4). Although reductions in cardiac output in these 2 experiments were important as an observed effect of exposure to Metarhizium anisopliae conidiospores, there appeared to be no biological significance for embryo hatching. The embryos continued to develop and hatched at the normal 7 to $8 \mathrm{~d}$ post fertilization. Also, the hatched larvae appeared normal in all respects. Thus, while the KW-ANOVA assesses significance in observed effects, the parametric ANOVA evaluates the apparent biological significance.

In Expt D, skeletal stunting and other abnormalities went undetected until hatch. Because these differences included skeletal abnormalities and skeletal stunting they also involved an important biological impact. Thus, both the KW-ANOVA and ANOVA for 'hatched normal' larvae indicated that these skeletal abnormalities were statistically significant at the high conidiospore density (Tables $3 \& 4$ ). 
In Expt E, growth of Metarhizium anisopliae was observed on mandibles of hatched larvae from all 3 conidiospore density exposures. Although this growth was apparent on the day of hatching, it had sloughed off of the mandibles by the following day. As in previous studies with Beauveria bassiana (Middaugh \& Genthner 1994), the biological significance of $M$. anisopliae growth on the mandibles of fish larvae remains to be interpreted.

In future studies we plan to examine different strains of Metarhizium anisopliae and investigate the role of spore associated, hydrolytic enzymes as virulence factors.

\section{LITERATURE CITED}

Boucias DG, Pendland JC, Latge JP (1988) Nonspecific factors involved in attachment of entomopathogenic deuteromycetes in host insect cuticle. Appl environ Microbiol 54:1795-1805

Dillon RJ, Charnley AK (1985) A technique for accelerating and synchronising germination of conidia of the entomopathogenic fungus Metarhizium anisopliae. Arch Microbiol 142:204-206

Donovan-Peluso M. Wasti SS, Hartmann GC (1980) Safety of entomogenous fungi to vertebrate hosts. Appl Entomol Zool 15:498

Drummond J (1994) Microbial control news from Australia. Soc Invertebr Pathol Newsl 26(2)

Fromtling RA, Kosnake SD, Jensen JM, Bulmer GS (1979) Fatal Beauveria bassiana infection in a captive American alligator. J Am vet Med Ass 175:934-936

Genthner FJ, Middaugh DP (1992) Effects of Beauveria bassiana on embryos of the inland silverside fish (Menidia beryllina). Appl environ Microbiol 58:2840-2845

Gillespie AT, Claydon N (1989) The use of entomogenous fungi for pest control and the role of toxins in pathogenesis. Pestic Sci 27:203-215

Hassan AEM, Charnley AK (1983) Combined effects of diflubenzuron and the entomopathogenic fungus Metar-

Responsible Subject Editor: T. Evelyn, Nanaimo, B.C., Canada hizium anisopliae on the tobacco hornworm, Manduca sexta. In: 10th Int Congr Plant Prot. BCPC Publications, UK, $p 790$

Middaugh DP, Genthner FJ (1994) infectivity and teratogenicity of Beauveria bassiana in Menidia beryllina embryos. Arch environ Contam Toxicol 27:95-102

Middaugh DP, Hemmer MJ, Goodman LR (1987) Methods for spawning, culturing and conducting toxicity tests with early life stages of four Atherinid fishes: the inland silverside, Menidia beryllina, Atlantic silverside, Menidia menidia, tidewater silverside, Menidia peninsulae and the California grunıon, Leuresthes tenuis. Report EPA-600/8-87/ 004. US Environmental Protection Agency, Gulf Breeze, FL

Middaugh DP, Hemmer MJ, Lores EM (1988) Teratological effects of 2,4-dinitrophenol, 'produced water' and naphthalene on embryos of the inland silverside Menidia beryllina. Dis aquat Org 4:53-65

Moscardi F (1989) Production and use of entomopathogens in Brazil. In: Roberts DW, Grandos RR (eds) Biotechnology, biological pesticides and novel plant-pest resistance for insect pest management. Insect Pathology Resource Center, Boyce Thompson Institute for Plant Research, Cornell University, Ithaca

Poprawski TJ, Maniania NK, Robert PH (1994) Contact toxicity of the mycotoxin destruxin E to Empoasca vitis (Gothe) (Hom., Cicadellidae). J appl Entomol 117:135-143

Siegel S, Castellan NJ Jr (1988) Nonparametric statistics for the behavioral sciences. McGraw-Hill, New York

StatSoft, Inc (1991) Complete statistical system: statistica, version 3.0. StatSoft, Inc, Tulsa, p 237-270

US EPA (1991) Methods for measuring the acute toxicity of effluents and recelving waters to freshwater and marine organisms. Report EPA/600/4-90/027. US Environmental Protection Agency, Washington, DC

Vey A, Farques J, Robert P (1982) Histological and ultrastructural studies of factors determining the specificity of pathotypes of the fungus Metarhizium anisopliae for scarabaeid larvae. Entomophaga 24:387-397

Weiser J (1982) Persistence of fungal insecticides: influence of environmental factors and present and future applications. In: Kurstak E (ed) Microbial and viral pesticides. Marcel Dekker, New York, p 531-557

Manuscript first received: October 24, 1994

Revised version accepted. March 9, 1995 